\title{
THE MULTILEVEL ANALYTIC PROCESS FOR SITUATIONAL PREVENTION (MAPS): IMPLEMENTING A NEW METHODOLOG Y FOR SECURITY AND CRIME PREVENTION
}

\author{
Silvia Ciotti Galletti \\ EuroCrime ${ }^{\circledR}$ - Research, Training and Consultancy \\ Tavarnelle V.P., Florence, ITALY \\ E-mail: silvia.ciotti@eurocrime.eu
}

\begin{abstract}
During the last ten years, issues connected to security (or organizational resilience) have become more and more relevant. After years of researches, data gathering and analysis, and after the first proposed and implemented solutions, it is actually clear that this issue is highly relevant worldwide and requests a multilevel and multidisciplinary approach. In fact, criminal, geopolitical, social, cultural and, in some cases, religious issues are deeply involved in criminal phenomena, connected to local political instabilities, poverty, terrorism as well as organised crime. Only a new methodology, aimed at a global approach to this problem, and strictly practical oriented, can help us to implement quick and effective solutions, most of all if a situational prevention approach is adopted as a main guideline.

In this paper, a global and integrated methodology is presented. This methodology adopts different techniques, software and approaches to support the decision makers along these phases: 1) data gathering and analysis; 2) realization of integrated situational prevention solutions; 3) validation of these solution; 4) final validated integrated situational prevention solutions.

Different aspects are involved in this new methodology, originally developed for maritime security and anti-piracy activities, and there are different possible outcomes as well as various fields in which it can be used for security and crime prevention. This is why this paper is connected to many different topics, as the human-centric decision support methodologies and concepts, the knowledge exploitation and multiagent systems, the dynamic multiple criteria decision analysis.
\end{abstract}

Keywords: decision making; situational prevention; Analytic Hierarchy Process (AHP); Analytic Network Process (ANP); Social Network Analysis.

\section{Introduction}

The criminological sciences have had a relevant development in the last 50 years. Criminology was born in the XIX century, at the beginning mainly as clinical criminology: a new science dealing with forensics and cultural anthropology. The first criminological theories were strictly connected with the new scientific theories, as Darwinism, and they tried to apply the scientific methodology to the crime analys is and, most of all, to the analys is of criminal behavior.

These first theories actually are highly questionable, and they have been abandoned many years ago. However, they still have the incommensurable value of having analyzed, for the very first time, crime and criminals by a scientific viewpoint, and not only by a moral or ethical one.

This scientific approach is increasingly relevant, and actually it lead to the splitting of criminology in different disciplines, all dealing with the crime event, the victims and the perpetrators. The clinical disciplines (as forensics) are still obviously very relevant, but the social approach is probably one of the main relevant. In fact, we can consider criminology as an interdisciplinary science, strictly connected to forensics as well as to law, psychology, psychiatry, anthropology, politics, sociology, and so on. We 
could say that all the scientific disciplines, and the methodologies, which are useful and relevant to analyze the crimes are welcome in criminology.

The new frontier to criminological analysis is actually represented by the use of new methodologies as the social network analysis, the data mining techniques, the problem solving crime analysis and the forecasting techniques to be adopted for the crime prevention.

\section{The Multilevel Analytic Process for Situational prevention (MAPS)}

\subsection{The rele vance of crime prevention}

Governments, public institutions, international organizations and law enforcement agencies pay a great attention to the crime prevention. In fact, to prevent a crime is relevant by different viewpoint: first of all, obviously, to avoid damages and sufferings to one or more victims; then, to try to readmitted the perpetrators in the society, stopping them from committing crimes and offering them other opportun ities. However, to be realistic, one of the most important reasons for crime prevention is to avoid the social costs of crime.

Crime is expensive. It causes direct damages and costs (the goods stolen, for instance, with the connected loss and the expenses for the insurance companies, or the costs for medical care for the victims) as well as indirect costs (the salaries for the law enforcement officers, the costs of the investigations, trials, custody...) and damages (e.g. if in a neighborhood there are many cases of burglary or vandalism, the economical value of the houses can seriously decrease).

Many tools and strategies have been adopted for crime prevention. All these tools have a cost, and a potential impact on different aspects of the life of the population. CCTVs, for instance, can have a strong impact on the privacy of people. The debate about the most efficient tool are still going on, and actually there is not a final solution. Again, to be realistic we should say that different tools are necessary for different places, times and situations. However, if we consider the most cost effective tools, usually they are belonging to the group of the situational crime prevention tools, studied in Environmental Criminology.

To identify the best tool (or set of tools) and strategy is not so easy, and shall be done case by case. Usually, it is necessary to choose among different possible solutions, and the decision criteria are various; moreover, in many cases to know all the involved variables it is necessary to make a preliminary analysis, involving different methodologies, as the social network analysis, the data mining techniques and the problem solving crime analysis. Then, when all the variables are clearly identified, it is necessary to focus on a set of options, and to go on with reliable decision making framework and methodologies.

To rely on a serious methodology is absolutely fundamental. It shall allow to include all the factors and criteria, and it shall be a flexible instrument which allow as well to take into consideration the opinions and past personal experiences of the expert performing the assessment. Allowing feedback and interactions, this tool could be considered also a forecasting instrument: in fact, it allows to represent different possible effects and consequences of the different adopted decisions. By this viewpoint, both the Analytic Network Process (ANP) and the Analytic Hierarchy Process (AHP) are the best solution.

\subsection{The MAPS methodology}

Since some years the EuroCrime® independent research center has adopted an integrated methodology based on the ANP framework to forecast criminal events and the developments of criminal activities in general. Successfully adopted firstly in the field of organized crime, actually this methodology has be en adapted also to terrorism, port security and maritime piracy. During the years, this methodology, called Multilevel Analytic Process for Situational prevention (MAPS), became increasingly complex and comprehensive, and actually it is an integrated tools which allow first of all a complete analysis of the criminal situation (analyzing the crime event, the victims, the perpetrators as well as the interaction among them), of the social and political framework, of the possible solutions and strategic plans based 
mainly on the situational crime prevention tools (Integrated Situational Prevention Projects, ISPPs). Then, the MAPS methodology allow a validation phase, in which the different ISPPs are examined and tested using the ANP and AHP methodologies. The final results is a validated ISPP (VISPP), which adoption is supported by a comprehensive analys is and an in depth scientific study.

\section{The Environmental Criminology}

\subsection{What is Environmental Criminology?}

Environmental Criminology is a field of research composed by a group of theories sharing a common interest in criminal events and in the immediate circumstances in which these events occur. According to one of the main theories in this field, all criminal events must be considered as confluences of victims or criminal targets, offenders, and laws in a particular time and space.

We can say that Environmental Criminology deals with crime analys is on three levels:

1. the understanding of the crime event;

2. the analysis of crime patterns;

3. the crime prevention and crime control.

For each of these three levels we have different theories and methodologies. Combining and adapting them to the different situations we can obtain the best results case by case.

All the theories approaching crime issues by an Environmental Criminology viewpoint are very practical. The main ones, organized around the three levels, are:

1. understanding the crime event:

- rational choice perspective;

- situational precipitators of crime;

- routine activity approach;

- crime pattern theory;

2. analys is of crime patterns:

- crime mapping and hot spots analysis;

- analysis of repeated victimization;

- geographic profiling;

- problem solving crime analysis;

3. crime prevention and crime control:

- crime prevention through environmental design;

- situational crime prevention and products design against crime;

- problem-oriented policing;

- broken window theory;

- intelligence-led polic ing.

\subsection{Situational Crime Prevention}

Without going too much in depth (owing to the complexity of these theories), we can say that following only one theory, and its suggestions, is not adequate to an effective crime analysis. In fact, these theories are very practical, and the results of their adoption vary a lot owing to time and space circumstances. These differences are particularly relevant at the third level, dealing with crime prevention and crime control.

This is why it is fundamental, first of all, to decide which kind of approach is the most suitable case by case. Then, an in depth analys is of the criminal phenomenon is necessary; however, the characteristics of this analysis can be very different in different situations. In fact, one of the most relevant innovations of the theories connected with Environmental Criminology is that in many cases it is possible to plan prevention and control strategies also before a crime is really committed. 
This concept may seem quite intuitive: in fact, to prevent is to intervene before that something happens 8in this case, the crime event). However, to have crime prevention you must first of all be aware of a crime risk, and in many cases this is possible only if one, or more crimes have been committed e.g. in a certain place. This is why very often the crime prevention is just the prevention of the repeating of crime events. For instance, usually it is common to have specific measures against burglaries (e.g. local police patrols, adoption of home alarms, watchdogs and so on) in a particular neighborhood only after that some burglaries have been committed there. Before these events, people are not aware to be at risk.

Situational prevention is slightly different. Its aim is to alter the situational determinants of crime as so to make crime less likely to happen. This could be done effectively also before that a crime is really committed, and we could say, by some viewpoints, "just in case". For instance, there are particular chairs designed to prevent theft of bags and other personal belongings (situational crime prevention through products design). Many libraries, pubs, restaurants and other public spaces make this chairs available to their customers not because they experienced thefts before, but "just in case", offering to the public a kind of an extra service.

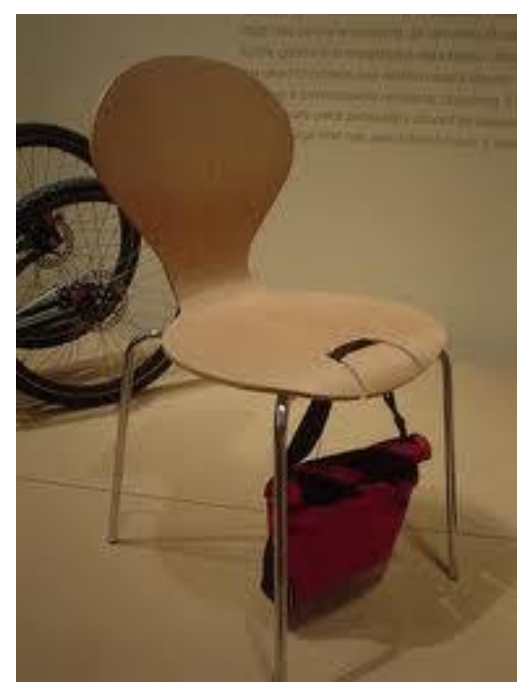

Figure 1. Design against crime chair.

Situational crime prevention has been criticized because it appears to be too simple, and most of all because it addresses crime events by a very practical viewpoint, not addressing the root causes but just preventing and avoiding the commission of criminal acts through the reduction of crime opportunities. This is why it can be considered as one of the tools to be adopted in preventing crimes, and not the only one; however, it is a very cost effective tool and can obtain very quick and immediate results. By this viewpoint, it is one of the best tools available to policy makers, most of all at a local level, and its adoption is increasing worldwide also in combination with other planning and strategic tools.

\section{The other integrating methodologies}

\subsection{A global strategy}

As previously said, even if situational crime prevention is a very effective tool it should be considered only as a part of a global strategy against crime. This tool is the more effective to adopt practical solutions, but it is necessary to have a strong previous analys is of the situation to plan an effective strategy. In many cases, according to the analys is and to the theories supporting it, it is possible to have many situational prevention options, and it is necessary to choose among them. 
The MAPS methodology requires an integrated analys is of the situation, based on the first two levels of Environmental Criminology (understanding the crime event and analysis of crime patterns) and connected theories. To these tools, the MAPS methodology adds some other data gathering and analysis tools.

Among these tools we can mention:

- Social Network Analysis, examining the human and social aspects of the crime event and crime links;

- Data mining techniques;

- Vulnerability Assessment.

The MAPS methodology combines these tools with the ones proposed by Environmental Criminology, choosing case by case the best suitable tools and gathering a huge amount of information. This is the first stage of the MAPS methodology, constituting the problem finding and setting related to a specific place and time.

\section{The Integrated Situational Prevention Projects (ISPPs)}

\subsection{A new tool}

The second stage of the MAPS methodology is the drafting of Integrated Situational Prevention Projects (ISPPs). Based on the data gathered during the first stage, on their processing and analys is, these projects presents different possible situational prevention solutions to be adopted in the specific case. They are very practical, and strictly connected to the time and space conditions, as well as to the social, economic, political and cultural situation to which the solution shall be apply.

The ISPPs are the final result of the problem analysis and solving activities, constituting the second MAPS stage. However, they are proposed solutions, and as such they can be considered all on the same level. This is why a third stage is necessary, in which the proposed ISPPs are evaluated and compared, their effects and consequences are examined and, after a decision making process, a final Validate Integrated Situational Prevention Project (VISPP) is proposed and adopted.

\section{The Validated Integrated Situational Prevention Project (VISPP)}

\subsection{The decision making and the final results}

The third MAPS stage is the decision making and taking phase. In this stage the proposed ISPPs are analyzed with the AHP and ANP methodologies. Both the methodologies are essential to support the decision making and taking activities; however, to be time effective in many cases it is not possible to adopt both the instruments. In these cases the preferable tool will be selected according to the predominating ISPP characteristics.

At the end of this stage, a Validated Integrated Situational Prevention Project (VISPP) will be proposed for the adoption to the interested subjects or institutions.

This global methodology, organized in three stages but encompassing also other different theories and methodologies and tools, has been successfully adopted in different cases (urban security planning, port security, and so on). It is a flexible methodology, based on a strong data gathering on one side and on the professional expertise and knowledge of the involved experts on another side. Adopting the MAPS methodology not only the actual and potential criminal situations are examined and analyzed, but also situational prevention projects are proposed; moreover, the methodology allows to validate these projects, and supports decision making and taking activities related to the adoption of one of these proposed projects. 


\section{REFERENCES}

ASIS INTL. (2009), Organizational Resilience: Security, Preparedness, and Continuity Management Systems-Requirements with Guidance for Use. American National Standard, ASIS SPC. 1-2009, Alexandria, Virginia, USA: ASIS INTERNATIONAL.

Clarke R. V., \& Eck J. (2003), Become a Problem-Solving Crime Analyst, London, UK: Jill Dando Institute of Crime Science.

Clarke R.V., \& Newman G. R. (2005), Designing Out Crime from Products and Systems, Crime Prevention Studies, volume 18, Monsey, NY, USA: Criminal Justice Press.

Dulli S., Furini S., \& Peron E. (2009), Data mining. Metodi e strategie, Milano, Italy: Springer-Verlag Italia.

Edwards A., \& Gill P. (edited by) (2006), Transnational Organised Crime, New York, NY, USA: Routledge.

Falcone D., De Felice F., \& Saaty T. L. (2009), Il decision making e i sistemi decisionali multicriterio, Milano, Italy: Hoepli.

Flick U. (2002), An Introduction to Qualitative Research, London, UK: Sage Publications Ltd.

Kay J. (2010), Obliquity. Why Our Goals are Best Achieved Indirectly, London, UK: Profile Books Ltd.

Knoke D., \& Yang S. (2008), Social Network Analysis. Second Edition, Series: Quantitative Applications in the Social Sc iences, Thousands Oaks, California, USA: Sage Publications Inc.

Morselli C. (2009), Inside Criminal Networks, Studies of Organized Crime, New York, NY, USA: Springer Science+Business Media, LLC.

Roiger R. J., \& Geatz M.W. (2004), Introduzione al Data Mining, Milano, Italy: The McGraw-Hill Companies s.r.l., Publishing Group Italia.

Smith J. M., Cornish D. B. (edited by) (2003), Theory for Practice in Situational Crime Prevention, Crime Prevention Studies, volume 16, Monsey, NY, USA: Criminal Justice Press.

Steinberg S. J., \& Steinberg S. L. (2006), GIS. Geographic Information Systems for the social Sciences. Investigating Space and Place, , Thousands Oaks, California, USA: Sage Publications Inc.

Tilley N. (edited by) (2005), Handbook of Crime Prevention and Community Safety, Cullompton, Devon, UK: Willan Publis hing.

Wortley R., \& Mazerolle L. (2008), Environmental Criminology and Crime Analysis, Cullompton, Devon, UK: Willan Publishing. 